\title{
Manguebeat, samba e experiência musical brasileira
}

\section{(4) Paulo Henrique Vieira de Souza}

Secretaria de Estado de Educação do Distrito Federal (SEEDF)

ph.vieiras@gmail.com

Fecha de recepción: 17/6/2020. Fecha de aceptación: 30/3/2021.

\section{Resumo}

Esse artigo visa estabelecer parâmetros para interpretação do Manguebeat segundo a experiência musical brasileira. A intenção é procurar chaves que sirvam a uma abordagem crítica da produção de Chico Science \& Nação Zumbi e Mundo Livre S/A. O achado parcial dessa reflexão sugere a relevância de uma noção expandida de samba no trabalho das duas bandas.

Palavras-chave: Manguebeat; Chico Science \& Nação Zumbi; Mundo Livre S/A; experiência musical brasileira; samba.

\section{Manguebeat, samba and Brazilian musical experience}

\begin{abstract}
This paper aims to establish parameters to the interpretation of Manguebeat according to the Brazilian musical experience. The intention is to seek keys to a critical approach for the production of Chico Science \& Nação Zumbi and Mundo Livre S/A. The partial finding of this reflection suggests the relevance of an expanded notion of samba in the two bands' work.


O Manguebeat, fenômeno midiático ancorado na produção musical de dois grupos brasileiros - Chico Science \& Nação Zumbi (CSNZ) e Mundo Livre S/A (MLSA) -, foi identificado por Pedro Alexandre Sanches, crítico musical de influentes veículos jornalísticos, como "primeira turbulência com contornos de movimento desde o tropicalismo" (2000, p. 287). No mesmo sentido, Idelber Avelar (2011) sugere que as bandas pernambucanas chegaram a uma formulação capaz de superar o fosso entre o que chama de "música jovem" (2011, p. 25) e o projeto musical de "potencial contestatório e emancipatório" (2011, p. 25) urdido nas décadas de 1960 e 1970, afirmando que CSNZ era "um grupo de música brasileira capaz de estabelecer um diálogo com a tradição sem ansiedade ou reverência" (2011, p. 27).

Esse texto busca estabelecer parâmetros para o julgamento dessas afirmações, que ecoam em parte da literatura acadêmica produzida sobre o tema, procurando apreender criticamente o papel da produção dessas bandas no fluxo da música popular-comercial brasileira. A intenção é encontrar nessa dinâmica de amplo espectro histórico uma chave de interpretação para seu trabalho.

\section{Experiência musical brasileira, a centralidade da canção popular-comercial e os estudos literários}

A expressão experiência musical brasileira relaciona as ideias de música e de nacionalidade. A interação entre essas duas noções foi trabalhada por Manoel Dourado Bastos (2009) a partir da contribuição de Antonio Candido (2000) para o debate sobre a literatura brasileira. Bastos (2009) visa compreender a constituição de um sistema musical em que se possa considerar consolidada uma expressão artística com características nacionais. A reflexão vincula, portanto, duas concepções disseminadas no mundo ocidental moderno, enfatizando sua historicidade: a ideia de música como esfera artística relativamente autônoma e a de nação como comunidade coesa, limitada e soberana.

Submetida ao que Paulo Eduardo Arantes (1992) identificou como possível lei geral da evolução mental brasileira, a saber, a dialética entre localismo e cosmopolitismo, ${ }^{1}$ a experiência musical no Brasil deu-se entre influências do sistema tonal em desenvolvimento na Europa e a interação local de sonoridades indígenas, africanas e ibéricas, estabelecidas gradualmente desde o século XVI. Esse universo sonoro constituiu ao longo do tempo manifestações musicais amalgamadas aos dilemas da formação brasileira, ${ }^{2}$ de onde se destacam dois pontos interessantes ao objetivo desse trabalho: uma aparente associação entre as ideias de síncope e de Brasil e a primazia da canção na experiência musical nacional.

1 Arantes (1992) observa que a perspectiva da dialética entre localismo e cosmopolitismo comanda a Formação da literatura brasileira.

2 Uma discussão aprofundada sobre os dilemas da formação da nação e a música é encontrada no primeiro capítulo da tese de Manoel Dourado Bastos (2009). 
O primeiro ponto será apresentado no tópico seguinte, voltado à discussão do samba; já o segundo pode ser brevemente esclarecido a partir de um texto panorâmico de Luiz Tatit (2004), que toca pontos relevantes das particularidades da experiência musical brasileira no século XX. O semioticista afirma que

\begin{abstract}
A atuação do corpo e da voz sempre balizou a produção musical brasileira. [...] Em todos os períodos, desde o descobrimento, a percussão e a oralidade vêm engendrando a sonoridade do país, ora como manifestação crua, ora como matéria prima da criação musical; ora como fator étnico ou regional, ora como contenção dos impulsos abstratos peculiares à linguagem musical (2004, p. 19).
\end{abstract}

A partir de então, Tatit se dedica à demonstração do amadurecimento de sonoridades de apelo corpóreo fortemente vinculadas ao canto e à dança até o registro das primeiras canções em máquinas de gravação com finalidade comercial. No fluxo da argumentação, entende-se que o âmbito corpóreo favoreceu a refração das sonoridades populares aos ideais da música desinteressada, contribuindo para a centralidade da canção e para a conformação de suas especificidades no contexto brasileiro. ${ }^{3}$

No mesmo texto, Tatit observa ainda como a reprodução mecânica do som delineou a adaptação do universo sonoro popular ao aparato tecnológico do momento, determinando aspectos do arranjo instrumental, da harmonia e melodia e até da duração da faixa, restrita aos 3 minutos: características que se tornariam comuns nessa modalidade artística inescapavelmente ligada ao comércio.

Visando enfatizar o traço da circulação comercial da canção e suas decorrências formais, Walter Garcia (2017) se propõe a entender essa modalidade de produção musical segundo a expressão canção popular-comercial brasileira, ressaltando simultaneamente seu vínculo com formas populares e seu caráter de objeto dependente dos interesses mercadológicos. Desse modo, Garcia (2017) considera ser possível entender essa produção cancional dentro de um conjunto articulado de

\begin{abstract}
a) produtores - compositores, cantores, músicos, produtores fonográficos - e obras, havendo o reconhecimento de influências, continuidades e rupturas, bem como de gêneros e de estilos [...]; b) receptores [...]; c) meios técnicos de gravação e reprodução, aliados a meios de transmissão em massa e a locais de venda - meios de transmissão e locais de venda que põem em contato obra/ produtores e receptores; e onde atuam diversos intermediários: programadores, apresentadores, repórteres, críticos, pesquisadores, publicitários, divulgadores, balconistas etc. (Garcia, 2017, p. 2).
\end{abstract}

O reconhecimento de um sistema consolidado a partir da canção popular-comercial brasileira ressoa a afirmação de Manoel Dourado Bastos (2012), que entende a consolidação da experiência musical nacional a partir do feito comercial e estético da Bossa Nova. Segundo Bastos,

3 A principal especificidade da canção segundo a concepção de Tatit, diz respeito à sua caracterização como canto manejado na tangente da fala, ou seja, à noção de que o canto decorre de uma intensificação da fala, tornando os aspectos musicais e literários indissociáveis. 
o advento da Bossa Nova, entendida na sua dupla acepção de objetivação artística e de rótulo no jargão jornalístico e publicitário, deu direito de cidade definitivo a uma argumentação sobre a "música popular brasileira" que privilegie sua dimensão estética. Não que isso tenha acontecido de súbito, afınal a Bossa Nova é resultado de um processo, uma dinâmica, uma experiência [...] (2012, p. 200).

O trecho arremata a ideia de que a dinâmica das sonoridades em interação, assimiladas pela indústria, desembocou num processo capaz de se estabelecer enquanto campo de reflexão. Dito de outro modo, é a conclusão de que a experiência musical brasileira se consolidou sob os termos contraditórios da indústria fonográfica, constituindo um sistema no qual a canção popular-comercial desempenha papel central.

Por fim, vale esclarecer que, mesmo com a reafirmação desse campo de debate como diferente tanto da literatura quanto da música, os estudos sobre canção ainda não estabeleceram domínio próprio, realizando-se entre departamentos das áreas de Letras, Música, Artes e Humanidades. Mesmo assim, conforme se procurou demonstrar, no caso brasileiro, estudos teóricos e críticos sobre a canção já alcançaram desenvolvimento considerável, por exemplo, na abordagem semiótica de Luiz Tatit $(2004,2012)$ e no aporte da tradição dialética inspirada por Antonio Candido, em que o papel da literatura brasileira na compreensão das formas sociais locais e de outras formulações artísticas tais quais o teatro, o cinema, a canção - é central. Na esteira desses estudos, se destacam Wisnik (2004a), Garcia (1999, 2013, 2017), Bastos (2009), Fischer (2016), Leite (2011).

\section{Síncope e samba}

Desde 1870, existem menções à palavra samba no Rio de Janeiro, mas ela só se popularizaria no contexto do comércio fonográfico em 1917, com a gravação, realizada por Baiano, de "Pelo telefone", canção registrada por Donga, um ano antes, na Biblioteca Nacional do Rio de Janeiro, como "samba carnavalesco". Dentre as decorrências do sucesso dessa gravação, uma das mais importantes para o argumento desse trabalho foi a elevação do vocábulo samba à expressão capaz de designar a transformação de uma gama de sonoridades afro-brasileiras em gênero de canção popular-comercial. O estudo de Sandroni (2001) indica esse aspecto do fenômeno tanto ao demonstrar a relação de "Pelo telefone" com manifestações populares anteriores a ela; quanto ao notar a transformação rítmica do samba amaxixado para o samba do Estácio. Assim, é possível entender o termo segundo uma amplitude semântica que entra em consonância com o mote do célebre ensaio de Muniz Sodré, Samba, o dono do corpo, em que o autor entende o samba como "aspecto da cultura negra - continuum africano no Brasil e modo brasileiro de resistência cultural - [que] encontrou em seu próprio sistema recursos de afirmação da identidade negra" (Sodré, 1998: p. 10. Grifo do autor). 
O principal achado de Sodré (1998) consiste em uma atribuição de sentido, politicamente comprometida e verossímil do ponto de vista histórico, ao aspecto formal da síncope, ${ }^{4}$ predominante na rítmica do samba. Segundo ele,

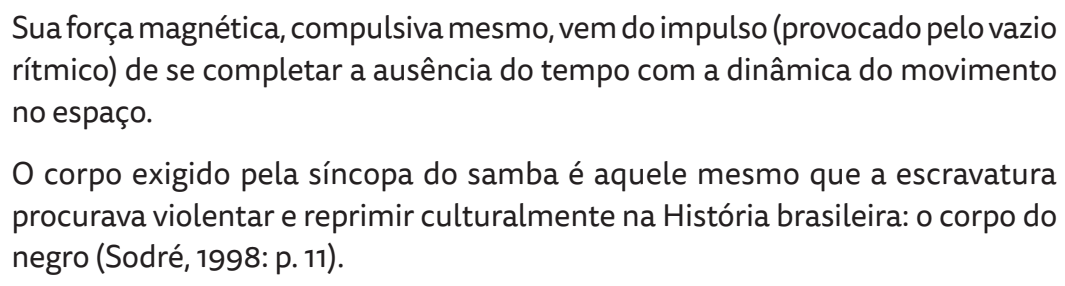

O corpo exigido pela síncopa do samba é aquele mesmo que a escravatura procurava violentar e reprimir culturalmente na História brasileira: o corpo do negro (Sodré, 1998: p. 11).

Para Sodré (1998), a síncope seria, mais do que característica marcante, o índice de identidade da sonoridade afro-brasileira a que ele chama samba. 0 argumento, construído com liberdade quase poética, ecoou em diversas teorizações a respeito do assunto: é possível encontrá-lo diretamente citado, por exemplo, em Wisnik (2004b), Sandroni (2001), Tatit (2004). Em “A Sonoridade Brasileira” (Tatit, 2004), o argumento de Sodré (1998) aparece subjacente ao intento de vincular voz, percussão e corporeidade como constantes interrelacionadas na constituição da sonoridade brasileira. Assim, indiretamente, o texto de Tatit (2004) contribui para a validação desse sentido expandido de samba, com potencial de generalizar-se para além da estabilização estilística de um padrão musical, e reafirma a preponderância do continuum africano sobre as sonoridades populares constituídas no Brasil.

Já Sandroni (2001), aproxima-se da discussão sobre a síncope principalmente por via da etnomusicologia, chamando atenção à contradição de tomá-la como fator característico do samba ou da brasilidade, quando o termo designa um conceito teórico da tradição musical ocidental que se refere ao desvio da rítmica regular. Em sua argumentação, Sandroni se volta à rítmica de tradições africanas, de lógica aditiva, onde se somam continuamente células de dois e três tempos, constituindo uma imparidade rítmica na qual inexiste a regularidade do compasso, o que tornaria o uso do termo "síncope" inadequado. Nesse sentido, Sandroni (2001) afirma que em muitos casos, rítmicas de sonoridades brasileiras seriam mais bem compreendidas pela lógica aditiva do que pela estrutura de compasso. Mesmo assim, o musicólogo reconhece que é pela ideia de síncope que elementos da rítmica africana tem se manifestado em sonoridades brasileiras. Conforme sua observação, "hoje em dia não são apenas os teóricos e os músicos de conservatório que falam das 'síncopes' brasileiras: a palavra entrou no vocabulário do leigo e dos músicos populares, conheçam eles ou não a leitura musical" (Sandroni, 2001, não paginado), e completa: “a síncope reiterada e elevada a norma muda de sentido, configurando um outro sistema que não é mais africano nem puramente europeu" (Sandroni, 2001, não paginado).

4 A fim de iniciar a discussão, se considerará a síncope (ou síncopa) como o efeito que ocorre quando um som executado em tempo fraco do compasso se prolonga até o tempo forte, promovendo a mudança da acentuação regular. 
Voltando ao sentido de samba proposto por Sodré (1998), nota-se que, apesar de pouco rigoroso do ponto de vista teórico, ele é capaz de abarcar uma diversidade de sonoridades afro-brasileiras e manter em seu núcleo significativo a noção de musicalidade sincopada, continuum africano, modo de resistência cultural brasileiro. Assim, o ensaio revela um conjunto de características que se estabelecem como linha subterrânea capaz de interligar três momentos distintos de sonoridades designadas como samba: as manifestações coletivas não mediatizadas anteriores à assimilação pela indústria fonográfica; as primeiras canções populares-comerciais que consolidaram o samba, as rádios e o comércio de fonógrafos; as diversas variações da ideia de samba após sua consolidação como gênero identificado com a brasilidade.

Conforme se percebe, a relação entre síncope, samba e Brasil tem raízes na dinâmica social, remetendo-se a dilemas de longa duração. Apesar disso, a partir dos anos 1930, uma tendência à valorização da mestiçagem em âmbito político favoreceu o surgimento de sambas nos quais se observava a exaltação patriótica de figuras como o mulato, a mulata, o moreno e a morena. ${ }^{5}$ Esse processo permitiu que o samba, referido principalmente pelo "paradigma do Estácio" (Sandroni, 2001, p. 32), passasse a ser entendido, cada vez mais, como índice quase oficial da nacionalidade, tornando-se definitivamente sinônimo de brasilidade e transformando-se em referência obrigatória à canção popular-comercial, como uma espécie de repertório comum, língua vernácula.

Assim, o samba tornou-se presença fundamental nos momentos decisivos da experiência musical brasileira em termos mercadológicos: em sua consolidação com a Bossa Nova; em seu desdobramento imediato, na canção de protesto; e até mesmo como decadência, no Tropicalismo. ${ }^{6}$ Após o golpe de 1964 e a derrota política de um projeto de formação nacional, o descompasso das experiências artísticas colocou dilemas que desembocaram no Tropicalismo e em sua opção por assumir as contradições da expressão musical comercial pela montagem de imagens aberrantes assumidamente vendáveis, estabelecendo um pacto festivo com o mercado.

A solução tropicalista corporificava a ideia de que a totalidade é incognoscível e toda síntese é falseadora. Essa premissa, tomada enquanto lei dentro da indústria fonográfica, elevava a comercialização à única mediação cultural real, finalidade última, e consolidava o modelo de segmentação de mercado. Nesse momento, consolidava-se o uso da expressão MPB, que se estabelecia como mais uma nomenclatura de nicho comercial, favorecendo o surgimento de outros rótulos como música romântica, música sertaneja, pagode, rock nacional etc. E o samba, apesar de, em certa medida, permanecer como pilar constitutivo da dita MPB, se desdobrava em subgêneros mais ou menos vendáveis.

5 Uma breve discussão sobre o tema pode ser encontrara em Sandroni (2010).

6 Esse trecho faz menção direta ao título do estudo de Pedro Alexandre Sanches (2000), Tropicalismo: decadência bonita do samba. 
Consumava-se o esfacelamento da experiência musical brasileira. Em pouco tempo, mesmo elaborações com reconhecido apuro técnico e intenção abertamente crítica se encontrariam limitadas a um nacional-desenvolvimentismo sem lastros sociais.

\section{A década de 1990 e o Manguebeat}

No início da década de 1990, diante do contexto político-econômico mundial e nacional, a ideia de nação brasileira se demonstrava cada vez mais inviável em um país cindido socialmente. A sensação de desagregação político-econômica unida aos desdobramentos internos da experiência musical mediada pela indústria fonográfica fazia com que o surgimento de expressões artísticas capazes de captar o conteúdo social dentro desse sistema parecessem miragem.

Nesse período, tomava corpo nas periferias de grandes cidades brasileiras, especialmente em São Paulo e no Rio de Janeiro, o rap e o funk (também referidos como hip-hop, charme, peso, balanço), manifestações cancionais ligadas a tendências da música negra estadunidense que eram, em grande medida, independentes do fluxo da canção popular-comercial brasileira. Sua expansão ocorria praticamente à margem das atenções do mercado fonográfico e seus procedimentos sonoros envolviam técnicas estranhas à linha hegemônica da experiência musical nacional: uso de samples e entoação da voz mais próxima da fala do que do canto. ${ }^{7}$ Essas manifestações revelavam midiaticamente uma sociabilidade radicalmente distinta da predominante na canção popular-comercial, dando condições de expressão a subjetividades periféricas diante da totalidade imaginada do país e atestando a violência como mediador social possível. ${ }^{8}$ A consideração do país por essa manifestação indicava um outro horizonte no qual já não se contemplava mais a experiência musical como esfera autônoma, nos termos da arte ocidental, e menos ainda a fantasia do cumprimento da vocação brasileira para nação em sentido moderno.

Em resposta a esse contexto, cerca de uma década depois, José Ramos Tinhorão (2004) e Chico Buarque (2004) iniciaram uma polêmica sobre a perda do lastro histórico da forma artística referida ao longo desse trabalho como canção popular-comercial. Esse debate se tornaria célebre por expressões vistosas como "morte da canção" e "fim da canção"."

7 Micael Herschmann afirma que "A trajetória que conduziu à afirmação do funk (no Rio de Janeiro) e do hip-hop (em São Paulo) como importantes fenômenos urbanos juvenis dos anos 90 fez-se, por um lado, à margem e, por outro, nos interstícios da indústria cultural" (2005, p. 20).

Além do breve texto em que Luiz Tatit (2018) defende que o rap é uma modalidade cancional, ver também a dissertação de Marcelo Segreto (2015) sobre o tema.

8 Ver Herschmann (2005).

9 A primeira expressão é retomada, por exemplo, no artigo de Marcos Nobre e José Roberto Zan (2010) e sugerido no de Luiz Tatit (2018); já a segunda, se encontra diretamente citada em Fernando Barros e Silva (2009) e José Miguel Wisnik e Arthur Nestrovski (2010). 
Era diante dessas mudanças estruturais, perceptíveis no início da década de 1990, que o Manguebeat ganhava reconhecimento nacional através de uma matéria encomendada a José Teles pela revista Bizz. ${ }^{10}$ Surgido como um coletivo de artistas residentes em Recife, portanto afastados do eixo Rio-SP e do centro da produção comercial cultural, o Manguebeat só se consolidou enquanto fenômeno midiático em 1994, quando CSNZ e MLSA lançaram os seus primeiros álbuns, ambos vinculados a grandes gravadoras: Da lama ao caos, de CSNZ, lançado pela Sony/Chaos; e Samba esquema noise, do MLSA, pela Warner/Banguela Records.

Ambos os álbuns foram festejados pela mídia especializada, que reconheceu neles a justaposição de informações locais (nacionais e regionais) e da cultura globalizada, perceptível na remissão à literatura de ficção científica, aos quadrinhos, ao cinema e, especialmente, às sonoridades pop. ${ }^{11} \mathrm{O}$ sucesso no mercado nacional, no entanto, foi menor do que o esperado. Em contrapartida, as condições favoráveis do comércio mundial da mercadoria fonográfica contribuíram para a sustentabilidade comercial do Manguebeat, que alçou CSNZ ao sucesso internacional, como expressão da world music fusion. A repercussão mundial deu sobrevida a CSNZ na Sony, garantindo a permanência do Manguebeat sob os holofotes da mídia brasileira. Uma discussão mais aprofundada sobre esse mecanismo pode ser encontrada em Silva (2008) e Souza (2014); o foco do presente trabalho recai, antes, sobre o impacto interno causado pela emergência do Manguebeat e de suas bandas, que foram capazes de inserirem-se no fluxo já débil da experiência musical brasileira e, ao mesmo tempo, dar forma a seus limites desde o seu interior.

A explicação corrente para o alcance desse feito, tem sua base em dois dos estudos pioneiros sobre o Manguebeat, realizados por Philip Galinsky (2002) e Carolina Leão (2002), onde os autores realçam um vínculo entre os pernambucanos e a Tropicália, justificado pelo reconhecimento do mecanismo da antropofagia oswaldiana como base para os procedimentos estéticos de ambos os grupos. Alguns anos depois, Herom Vargas (2007) procuraria fazer uma revisão da discussão, aprofundando-a e problematizando-a, visto que os próprios mangueboys, expressão pela qual os integrantes do Manguebeat referiam-se a si, recusassem a associação direta com os tropicalistas. Apesar de seus esforços e da integração de novas vozes ao debate, a posição final do argumento de Vargas não difere muito de seus antecessores, concluindo que "a despeito do que alguns mangueboys comentam, a cena Mangue tem uma dívida importante com o Tropicalismo passível de ser medida pelo caráter experimental e antropofágico de ambos" (Vargas, 2007, p. 85, grifo do autor).

Com vistas em intervir nessa discussão, observe-se um trecho de entrevista em que Zero Quatro, integrante do MLSA, fala sobre o tema a Herom Vargas.

10 Ver capítulo de José Teles (2000) sobre o Manguebeat.

11 Relatos sobre a recepção desses álbuns pela crítica jornalística especializada em música podem ser encontrados em Ricardo Alexandre (2013) e José Teles (2000). 
[...] É a mesma coisa da comparação com o Tropicalismo, que é outra história recorrente. É como comparar hippie com punk. O punk surgiu como uma forma de dar um chute no estômago do hippie. [...] Ao mesmo tempo, você não tem como contestar que o punk tem algum vínculo com o hippie porque vem de um mesmo eixo [...]. Então, é a mesma coisa do Mangue com o Tropicalismo. A gente não nega algum parentesco. [...] Mas o cosmopolitismo deles tinha um viés muito da indústria de massa, aquela coisa do Chacrinha... Só que, do final dos anos 1970 para cá, o pop mais alternativo, que tinha a semente da provocação, da contestação, começou a ser um pop de resistência a essa coisa da massificação, da indústria. [...] É aquela coisa do slogan punk: "é veneno na máquina". Uma coisa a que o Tropicalismo nunca se propôs é isso de ter um vírus de destruição da máquina (Zero Quatro apud Vargas, 2007).

Devido a ser um dos principais articuladores do Manguebeat, não surpreende o fato de Zero Quatro perceber com clareza os nós causadores da polêmica e atuar sobre eles. De início, a ideia de um eixo comum a manifestações distintas permite o estabelecimento de um elo que não precisa de referências diretas. Depois, ao falar em cosmopolitismo, o artista dribla a desgastada expressão antropofagia, interrompendo o lugar-comum disseminado nas reflexões sobre o Manguebeat, segundo o qual a assimilação artística de influxos internacionais seria "invenção" modernista ou tropicalista. Por fim, Zero Quatro salienta ainda a intenção crítica do Manguebeat ante o mercado, tomando posição no debate que, demonstra saber, se dá no campo do adversário. A manifestação de Zero Quatro tem vetor predominantemente oposto ao da Tropicália e pode ganhar ainda mais força caso seja iluminada pelas elaborações cancionais do MLSA.

Restaria, assim, averiguar de que maneira as canções produzidas pelo Manguebeat respondem ao posicionamento teórico de Zero Quatro. A realização dessa tarefa, de importância fundamental para a avaliação do fenômeno encabeçado pelas bandas pernambucanas, demandaria um aprofundamento inviável ao espaço desse artigo, motivo pelo qual a reflexão se restringirá à observação panorâmica de um aspecto central para a compreensão do gume crítico de sua produção, considerando algumas de suas canções e passando brevemente pelos primeiros álbuns de cada grupo.

A observação dos títulos dos álbuns deixa ver a recorrência de termos que se remetem direta ou indiretamente a um campo semântico associado a cultura afro-brasileira - Samba esquema noise (1994), Guentando a ôia (1996), Carnaval na obra (1998), Afrociberdelia (1996), Rádio S.Amb.A (2000). Ao levar em conta as canções e suas características, essas referências tornam-se ainda mais latentes e o samba ganha destaque, seja em imagens, na citação de seus símbolos, na emulação e derivação de sua sonoridade ou na sua transformação em tema. Essa presença constante, mas sub-reptícia, transforma-o em uma fixação.

O conexão entre samba e Manguebeat pode revelar a linha profunda de acumulação pela qual CSNZ e MLSA acessaram o que ainda restava da experiência musical e os destroços do projeto de Brasil enquanto nação. Em geral, a bibliografia do 
Manguebeat entende o samba como mais uma entre as diversas sonoridades locais utilizadas pelos mangueboys em suas composições. ${ }^{12}$ Visão nada surpreendente, já que está sugerida em uma das canções mais conhecidas dos pernambucanos:

Eu vou fazer uma embolada, um samba, um maracatu

Tudo bem envenenado, bom pra mim e bom pra tu

Pra gente sair da lama e enfrentar os urubu ("A cidade", Da lama ao caos)

A presença estrita de características musicais que se refiram ao gênero estabilizado como samba, entendido hegemonicamente, conforme já se viu, segundo o paradigma do Estácio, será encontrada na produção do MLSA, mas muito raramente em CSNZ. Isso acontece porque as misturas sonoras promovidas pela banda de Zero Quatro em quase nada se assemelham àquelas constituídas por Chico Science e seu grupo, para quem no polo das sonoridades locais foram mais decisivas as tradições regionais pernambucanas do que as sonoridades associadas à identidade nacional.

A ausência, em CSNZ, de um samba musicalmente identificável sem outras mediações, não impede que a sua presença se materialize em noção estendida. Esse samba sui generis tem sentido deslocado musical e ideologicamente, soando mais como tensão do que referência celebrativa; mais como disputa da tradição do que como propaganda de si. É tentativa de reestabelecer a linha subterrânea composta como musicalidade sincopada, continuum africano, modo de resistência cultural brasileira. Ao mesmo tempo, no MLSA a referência sonora é mais direta, expressa na escolha do instrumental, em modelos rítmicos e numa identidade melódico-harmônica que sugere o samba estabilizado, apesar disso, a dissonância também se faz presente no desvio do ethos sambista consagrado nacionalmente: não há conciliação ou congraçamento. 0 fio que liga essa expressão à experiência musical nacional e um grupo ao outro, fazendo do Manguebeat um fato coeso, é a retomada não conservadora da tradição musical afro-brasileira, tanto a retrabalhada pelo mercado fonográfico, quanto aquela relativamente restrita a localidades específicas, ambas participantes do amplo leque de sonoridades de apelo corpóreo marcado pela presença africana na vida social brasileira.

Por exemplo, em Da lama ao caos (1994), o samba aparece, além do caso já citado de "A cidade", em uma das faixas de maior sucesso comercial: "Samba makossa". Conforme demonstrado em Souza (2014), o primeiro álbum de CSNZ reclama uma interpretação que considere as faixas e o material gráfico como partes de um conjunto integrado pela acumulação de significados. Desse modo, símbolos recorrentes como lama, caos, caranguejo, overdrive, Zumbi, Lampião se presentificam por associação, mesmo quando não são diretamente referidos. Também por essa lógica, a faixa "Samba Makossa" insere transversalmente no álbum uma ideia de samba como campo de disputa.

12 Ver, por exemplo, os já citados Philip Galinsky (2002) e Herom Vargas (2007). Exceções recentes se encontram em Locoselli (2019) e Souza (2021). 
Várias das características musicais de "Samba Makossa" são encontradas em outras faixas, sugerindo uma associação entre a noção de samba ali apresentada e a sonoridade de CSNZ. Essa hipótese é confirmada pela contínua remissão ao termo presente nos demais álbuns do grupo e, especialmente, por canções que, assim como "Samba Makossa", realizam uma disputa a respeito do sentido do samba. Nessa leva, pode-se incluir "Samba do lado", presente em Afrociberdelia (1996), faixa em que a palavra samba se repete por 49 vezes, atrelando-se a uma tomada de posição nada conciliatória:

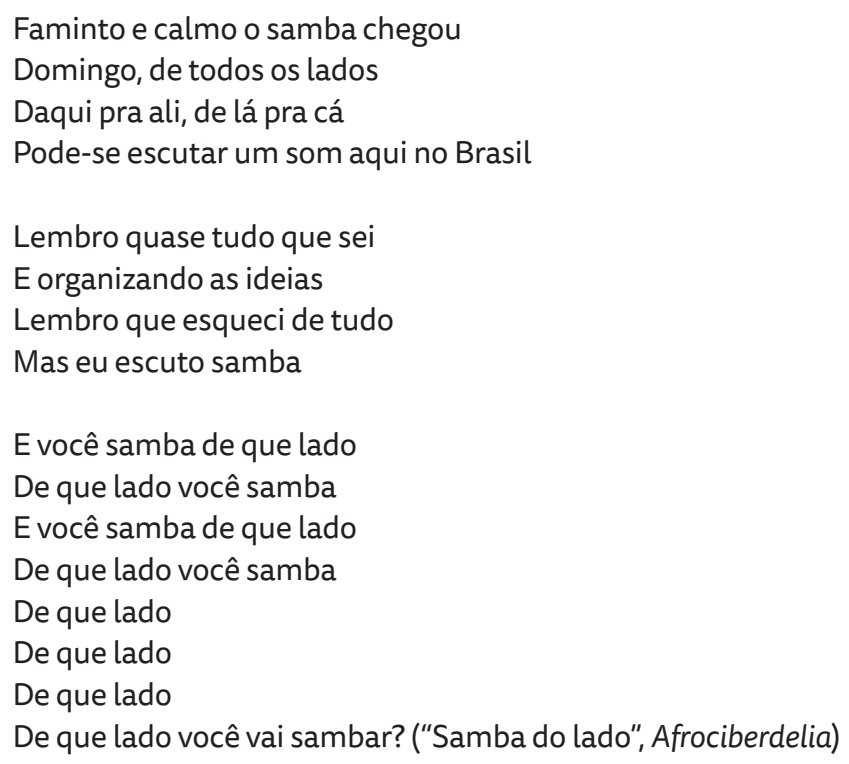

Mais marcante ainda é a disputa encenada no primeiro álbum da Nação Zumbi sem Chico Science, ${ }^{13}$ Rádio S.Amb.A. (2000), em que o samba aparece, desde o título, desvirtuado. A grafia, entrecortada por pontos, utiliza-se de maneira subversiva de maiúsculas e minúsculas, causando um efeito visual de estranhamento. Por associação, a palavra parece participar do universo tecnológico dos códigos de programação informática, sugerindo que o samba grafado dessa maneira tem relação com a modernidade e com as habilidades misteriosas restritas a iniciados. A confirmação dessas impressões se dá por informação presente no encarte, onde explica-se que S.Amb.A é sigla para Serviço Ambulante de Afrociberdelia. No plano musical, o álbum inicia-se pela afirmação de que a Rádio S.Amb.A vem "Do mote do doutor Charles Zambohead" (Nação Zumbi, 2000), codinome que Chico Science pretendia usar no terceiro álbum de CSNZ, e segue declarando:

Tá tudo inteirado pra segurar esse tom Então peguei pela beca no meio da graça

Abri-lhe o bucho e arranquei-lhe as tripas

Só pra ver que som dava

Se era de bamba, bamba, bamba 


\author{
Mandaram arrancar as tripas \\ Mandaram arrancar as tripas \\ Mandaram arrancar as tripas \\ Do samba ("Arrancando as tripas". Rádio S.Amb.A.)
}

Rádio S.Amb.A. (2000) fecha de maneira brutal o ciclo da discussão do samba pela Nação Zumbi: “Arrancando as tripas", a releitura de drum'n'bass realizada em "Lo-Fi Dream", as referências a Jorge Ben, Madame Satã e a regravação em versão industrial de "Jornal da Morte", canção de Roberto Silva, soam como declaração aberta da intenção de discutir o samba por dentro, chegando ao limite dessa experiência. Observado em perspectiva, esse álbum formula também o esgotamento do compromisso da Nação Zumbi com o Manguebeat. Em Rádio S.Amb.A. (2000), a banda recusou a sobrevida pela exploração fantasmagórica da figura de seu ex-frontman, afastando-se também do projeto do qual Science tornou-se ícone. $O$ álbum estabeleceu uma relação de respeito com a história da banda em uma continuidade do projeto musical sem afogamento na repetição inócua de si mesma. O desmantelamento do samba realizado pela Nação Zumbi é um enfrentamento criativo do que havia consagrado a banda.

Não por coincidência, esse primeiro passo de ruptura/permanência precisou ser dado fora de uma grande gravadora: o álbum foi lançado pela YB Music, tornando o seu alcance muito menor do que o de qualquer um dos seus três antecessores. Pela primeira vez, a Nação Zumbi se viu no meio "alternativo", rompendo com um dos principais pilares de sustentação do Manguebeat, a mídia hegemônica. Esse é também o primeiro passo da transformação de uma das principais bandas brasileiras da década em mais uma banda - uma das mais importantes - do então crescente mercado musical independente brasileiro.

No mesmo ano, MLSA também lançava um álbum com ares de encerramento de ciclo, demonstrando que a sonoridade desenvolvida pela banda até ali tornava-se finalmente vendável. Por pouco (2000) era ao mesmo tempo ápice mercadológico do grupo e limite do projeto estético do Manguebeat. Oálbum, lançado pela Abril Music, teve hits de sucesso e consolidou a associação entre a banda e o samba para um público mais amplo. Em todo o disco, o samba - nesse caso, muito mais próximo do padrão hegemônico - é presença ostensiva, sendo inclusive tema da primeira faixa, "Mistério do Samba". A expressão, além de referência direta ao trabalho de Hermano Vianna (2004), discute a aura de misticismo do samba. Em sua letra, cantada por Zero Quatro sobre um arranjo que mistura samba, rock e música latina, o mistério acaba sendo a possibilidade de existência de algo que se caracteriza por não ser.

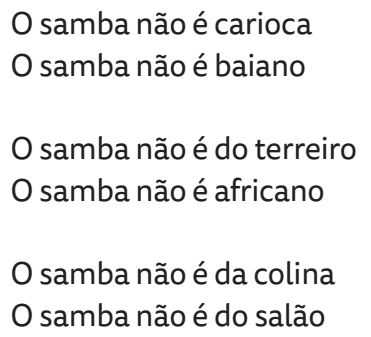




\author{
O samba não é da avenida \\ O samba não é carnaval \\ O samba não é da tv \\ O samba não é do quintal ("O mistério do samba". Por pouco)
}

A letra se estabelece pela inclusão da negativa às afirmações enunciadas como tentativas de explicação do samba, induzindo a uma audição cerebral, onde o receptor exercita a construção da sentença afirmativa enquanto ouve a negativa. O resultado desse jogo de sentidos repetido por quase quatro minutos é de uma saturação que culmina nos versos

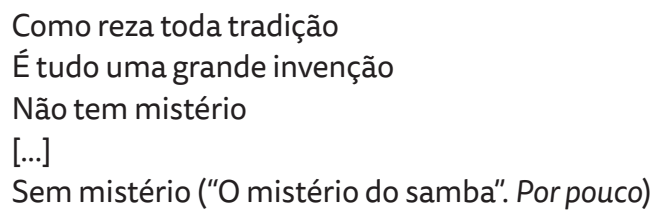

O samba como símbolo místico da união nacional, se transforma no samba sem mistério, inventado pela tradição da qual participam/não participam os interesses regionais e nacionais. Despido de sua aura, torna-se um samba da falta. Essa canção, colocada no início do álbum, compõe um sentimento de descrença que se encontra associado ao restante da produção da banda, sendo possivelmente a sua maior marca: a mistura entre a vivência da falta e uma sonoridade sincopada e convidativa ao movimento dançante. Essa formulação de aparente incoerência é muito do que produz a força da presença do samba nos álbuns anteriores e encontra formulação feliz em algumas faixas de Por pouco (2000), mas começava a se aproximar de maneirismo. Apesar disso, a ironia rigorosa que marca a dicção de Zero Quatro transforma até mesmo o maneirismo em vetor crítico: há no álbum cinco versões de canções alheias ("Mexe mexe", de Jorge Benjor; “Treme-treme”, versão para "Shakin’ All Over", de Johnny Kidd and the Pirates; "Lourinha Americana", de Mestre Laurentino; "Minha Galera”, de Manu Chao; e "Garota de Ipanema”, de Vinícius de Moraes e Tom Jobim), algo inédito em álbuns autorais da banda até então, e uma gritante versão da própria banda ("Melô das Musas" é a junção de duas canções do primeiro álbum em novo arranjo, "Musa da Ilha Grande" e "Uma mulher com W maiúsculo"). Assim, pela primeira vez a descrença parece ganhar referente direto, tornando-se um sintoma do esgotamento do projeto levado a cabo pela banda até então.

O resultado do álbum na trajetória do MLSA é a ruptura definitiva com as grandes empresas do mercado fonográfico e a interrupção do fluxo de lançamentos a cada dois anos. Seu álbum seguinte só seria lançado quatro anos depois, apresentando um processo de experimentação no qual a banda mergulharia dali em diante na busca de encontrar novamente a medida da formulação eficaz das tensões da realidade. Depois de 2000, CSNZ e MLSA precisaram reinventar-se: o Manguebeat ficou anacrônico. 
Esse breve percurso buscou demonstrar como foi decisiva na formulação do Manguebeat a retomada de sonoridades afro-brasileiras, que muitas vezes se manifestaram sob uma noção expandida de samba. É da interação entre essa musicalidade (oriunda das contradições de um país sem ilusões de integração nacional) e as informações, interesses e indiferença do contexto global que surgem as canções de CSNZ e MLSA.

Resta, ainda, a tarefa de analisar detidamente as produções dessas bandas (e de outros artistas trazidos à tona por elas) no período de 1994 a 2000, a fim de observar a plausibilidade da hipótese, apontada algumas vezes nesse texto, de que, assim como o rap e o funk formularam os limites da canção popular-comercial a partir de um eixo externo a ela, o Manguebeat formalizou os mesmos impasses segundo os termos da indústria fonográfica, sendo simultaneamente um vetor de força para sua superação e expressão de sua decadência; ou, em linguagem mais apropriada ao assunto, sendo crustáceo com cérebro em busca de superar o ciclo do caranguejo e parabólica enfiada na lama desse manguezal a que chamam Brasil. ${ }^{14}$ 


\section{Bibliografia}

" Alexandre, R. (2013). Cheguei bem a tempo de ver o palco desabar: 50 causos e memórias do rock brasileiro (1993-2008). Porto Alegre: Arquipélago Editorial.

"Arantes, P. E. (1992). Sentimento da dialética na experiência intelectual brasileira: dialética e dualidade segundo Antonio Candido e Roberto Schwarz. Rio de Janeiro: Paz e Terra.

"Avelar, I. (2011). O manguebeat e a superação do fosso entre o nacional e o jovem na música popular. Em Outra Travessia, Florianópolis, n. 11.

"Bastos, M. D. (2009). Notas de testemunho e recalque - Uma experiência musical dos traumas sociais brasileiros em Chico Buarque e Paulinho da Viola (de meados da década de 1960 a meados da década de 1970). Tese (Doutorado em História). Assis, UNESP, Faculdade de Ciências e Letras de Assis.

" Bastos, M. D. (2012). Formação e Música no Brasil - elementos para um debate. Em Corrêa, A. L., Pilati, A., Costa, D. M., Bastos, H. (Orgs.). O Brasil ainda se pensa: 50 anos de Formação da Literatura Brasileira. Vinhedo-SP: Editora Horizonte.

"Buarque, C. (2004). O tempo e o artista: a canção, o rap, Tom e Cuba, segundo Chico. Em Folha de S. Paulo, São Paulo, ano 84, n. 27.661, 26 dez. 2004. Folha llustrada, p. E4. Entrevista concedida a Fernando de Barros e Silva. <http://www1.folha.uol.com. $\mathrm{br} / \mathrm{fsp} /$ ilustrad/fq2612200408.htm >. Consulta: 23 fevereiro de 2018.

"Candido, A. (2000). Formação da literatura brasileira: momentos decisivos. Belo Horizonte - Rio de Janeiro: Editora Itatiaia.

"Fischer, L. A. (2016). Como ensinar o que aprendi sem perceber. Em Fischer, L. A. e Leite, C. A. (Orgs.). O alcance da canção- estudos sobre música popular. Porto Alegre: Arquipélago Editorial, 2016.

"Galinsky, P. (2002). "Maracatu Atômico": tradition, modernity, and postmodernity in the mangue movement of Recife, Brazil. New York: Routledge.

" Garcia, W. (1999). Bim Bom: a contradição sem conflitos de João Gilberto. São Paulo: Paz e Terra.

" Garcia, W. (2013). Melancolias, Mercadorias: Dorival Caymmi, Chico Buarque, o Pregão de Rua e a Canção Popular-Comercial no Brasil. Cotia-SP: Ateliê Editorial.

" Garcia, W. (2017). Conceitos, análises e ideias de Antonio Candido para quem estuda a canção popular. Em Informe IEB, Instituto de Estudos Brasileiros, Especial Antonio Candido.

"Herschmann, M. (2005). O funk e o hip-hop invadem a cena. Rio de Janeiro: Editora UFRJ.

"Leão, C. C. (2002). A maravilha mutante: Batuque, sampler e pop no Recife dos anos 90. Dissertação (Mestrado em Comunicação). Recife, UFPE, Centro de Artes e Comunicação.

"Leite, C. A. (2011). Catulo, Donga, Sinhô e Noel: a formação da canção popular urbana brasileira. Dissertação (Mestrado em Letras). Porto Alegre, UFRGS, Programa de Pós-Graduação em Letras da Universidade Federal do Rio Grande do Sul.

"Locoselli, L. (2019). De rocks, murgas e maracatus: o fazer musical e a construção do "local" sob o neoliberalismo latino-americano da virada do século. Um estudo 
comparativo das bandas Bersuit Vergarabat (Argentina) e Chico Science \& Nação Zumbi (Brasil). Tese (Doutorado em Letras). São Paulo: USP, Programa de PósGraduação em Língua Espanhola e Literaturas Espanhola e Hispano-Americana.

"Nobre, M. e ZAN, J. R. (2010). A vida após a morte da canção. Em Serrote, São Paulo: Instituto Moreira Salles, n. 6, nov. 2010. <https://revistaserrote.com.br/2011/07/avida-apos-a-morte-da-cancao/>. Consulta: 23 de fevereiro de 2018.

"Sanches, P. A. (2000). Tropicalismo: decadência bonita do samba. São Paulo: Boitempo Editoral.

"Sandroni, C. (2001). Feitiço Decente: transformações do samba no Rio de Janeiro. Rio de Janeiro: Jorge Zahar Editor Editora UFRJ.

"Sandroni, C. (2010). Categorias raciais e gêneros musicais gravados no Rio de Janeiro dos anos 1930 e 1940. Em Revista USP, São Paulo, no. 87, pp. 131-143.

"Segreto, M. (2015). A linguagem cancional do rap. Dissertação (Mestrado em Linguística). São Paulo, USP, Faculdade de Filosofia, Letras e Ciências Humanas.

"Silva, F. B. (2009). O fim da canção (em torno do último Chico). Em Serrote, São Paulo: Instituto Moreira Salles, n. 3, nov. 2009. <https://www.revistaserrote.com. $\mathrm{br} / 2011 / 06 / 0-$ fim-da-cancao-em-torno-do-ultimo-chico >. Consulta: 23 de fevereiro de 2018 .

"Silva, G. P. (2008). "Mangue": moderno, pós-moderno, global. Dissertação (Mestrado em Sociologia). São Paulo, USP, Faculdade de Filosofia, Letras e Ciências Humanas.

"Sodré, M. (1998). Samba, o dono do corpo. Rio de Janeiro: Mauad.

"Souza, P. H. V. (2014). Experiência musical brasileira e canção pop na década de 1990: um estudo sobre Chico Science e Nação Zumbi em perspectiva formativa. Dissertação (Mestrado em Literatura). Brasília, UnB, Departamento de Teoria Literária e Literaturas.

"Souza, P. H. V. (2021). Manguebeat e samba: o sistema cancional brasileiro em tempos de neoliberalismo. Tese (Doutorado em Literatura). Brasília, UnB, Departamento de Teoria Literária e Literaturas.

" Tatit, L. (2004). A Sonoridade Brasileira. Em O Século da Canção. Cotia-SP: Ateliê Editorial.

" Tatit, L. (2012). O cancionista. Composição de canções no Brasil. São Paulo: Editora da Universidade de São Paulo.

"Tatit, L. (2018). Cancionistas invisíveis. <http://www.luiztatit.com.br/artigos/ artigo?id=29/Cancionistas-Invis\%C3\%ADveis.html>. Consulta: 23 de fevereiro de 2018.

"Teles, J. (2000). Do Frevo ao Manguebeat. São Paulo: Editora 34.

" Tinhorão, J. R. (2004). Era uma vez uma canção. Em Folha de S. Paulo, São Paulo, ano 84, n. 27.542, 29 ago. 2004. Mais!, p. 4-6. Entrevista concedida a Pedro Alexandre Sanches. <http://www1.folha.uol.com.br/fsp/mais/fs2908200404.htm>. Consulta: 23 de fevereiro de 2018.

"Vargas, H. (2007). Hibridismos musicais em Chico Science \& Nação Zumbi. Cotia-SP: Ateliê Editorial.

"Vianna, H. (2004). O Mistério do Samba. Rio de Janeiro: Jorge Zahar Editor Editora UFRJ.

"Wisnik, J. M. (2004a). O Minuto e o Milênio ou Por Favor, Professor, Uma Década de Cada Vez. Em Wisnik, José Miguel. Sem receita. São Paulo: Publifolha. 
"Wisnik, J. M. (2004b). Getúlio da Paixão Cearense (Villa-Lobos e o Estado Novo). Em Squeff, E. e Wisnik, J. M. O nacional e o popular na cultura brasileira. Música. São Paulo: Brasiliense.

"Wisnik, J. M. e Nestrovski, A. (2010). O fim do fim da canção. [s.l]: Rádio Batuta, Instituto Moreira Salles, 29 abr. 2010. Série de aulas-show / podcast. <http://radiobatuta. com.br/programa/o-fim-da-cancao-o-fim-do-fim-da-cancao/>. Consulta: 23 de fevereiro de 2018.

\section{Referências Discográficas}

" Chico Science \& Nação Zumbi. (1994). Da Lama ao caos. Rio de Janeiro: Sony Music (Chaos).

" Chico Science \& Nação Zumbi. (1996). Afrociberdelia. Rio de Janeiro: Sony Music (Chaos).

" Mundo Livre S/A. (1994). Samba esquema noise. São Paulo: Banguela Records (Warner Music).

" Mundo Livre S/A. (1996). Guentando a ôia. Rio de Janeiro: Excelente Discos (PolyGram).

" Mundo Livre S/A. (1998). Carnaval na obra. Rio de Janeiro: Excelente Discos (PolyGram).

" Mundo Livre S/A. (2000). Por pouco. São Paulo: Abril Music.

"Nação Zumbi. (2000). Rádio S.Amb.A. São Paulo: YB Music. 